\title{
Neuropsychiatric lupus erythematosus, cerebral infarctions, and anticardiolipin antibodies
}

\author{
Roderick A Fields, Wilmer L Sibbitt, Hala Toubbeh, Arthur D Bankhurst
}

\begin{abstract}
Anticardiolipin antibody (aCL) has been associated with thromboembolic phenomena, including stroke, in certain patients with systemic lupus erythematosus(SLE); however, the relation between this antibody and the central nervous system manifestations of SLE is unknown. Serum samples and cerebrospinal fluid from five patients with SLE and acute central nervous system manifestations were assayed for the presence of aCL. Anticardiolipin antibody was identified in sera from four of the five patients but in none of the cerebrospinal fluid samples. Nuclear magnetic resonance imaging showed 'infarct-like' lesions in these four patients. This preliminary study suggests that a correlation between serum aCL and cerebral infarcts in central nervous system lupus may potentially exist. From this limited study it seems unlikely that aCL has a direct pathogenic role in the diffuse encephalopathy of acute central nervous system lupus.
\end{abstract}

Anticardiolipin antibodies (aCLs) are antiphospholipid antibodies with a related specificity to the lupus anticoagulant. ${ }^{12}$ Anticardiolipin antibody has been detected in patients with systemic lupus erythematosus (SLE) ) $^{3-5}$ and other rheumatological and non-rheumatological entities. $^{6-11}$ The presence of aCL is associated with thrombosis in patients with or without identifiable connective tissue disease. ${ }^{9} 12 \quad 13 \mathrm{~A}$ hypercoagulable state promoted by $\mathrm{aCL}$ has been postulated, in which aCL interacts with endothelial surfaces and platelet membranes to reduce prostacyclin production and increase platelet adhesiveness. ${ }^{14}$ An association of aCL with cerebral infarction has been reported both in patients with SLE and in patients with other disorders. ${ }^{16-18}$

Central nervous system involvement in SLE is common ${ }^{19}$ and is manifested by headaches, psychiatric syndromes, organic brain syndrome, seizure disorder, cranial neuropathy, and movement disorder. ${ }^{20-25}$ Clinically, diffuse cerebritis (diffuse lupus encephalopathy) is the most common form of central nervous system lupus and is characterised by acute organic brain syndrome, psychosis, or seizures. ${ }^{20}$ Diffuse cerebritis is best defined as the presence of diffuse or shifting focal central nervous system manifestations not readily explained by the presence of infection, stroke, haemorrhage, steroid psychosis, or aseptic meningitis. Several reports have suggested that autoantibodies may play a part in the pathogenesis of central nervous system lupus ${ }^{26} 27$ and are most often associated with diffuse cerebritis. $^{28} 29$ The presence of such antibodies would be manifested by the absence of acute infarction and by the presence of reversible oedema of neural tissue. ${ }^{30}$ Recently, aCLs have been shown to cross react with cephalin and sphingomyelin, which are components of neuronal tissue. ${ }^{31}$ The importance of anticardiolipin as an antineuronal antibody has not been studied, however.

In this study we assayed for aCLs in the sera and cerebrospinal fluid of five patients with neuropsychiatric SLE and attempted to relate the presence or absence of these antibodies to important clinical and laboratory measures of disease activity.

\section{Patients and methods} PATIENTS

All five patients were under the care of the division of rheumatology and clinical immunology at the University of New Mexico School of Medicine. The diagnosis of SLE was established using American Rheumatism Association criteria. ${ }^{32}$ Serum and cerebrospinal fluid samples were obtained at admission. The diagnosis of diffuse encephalopathy and the presence of typical physical findings was confirmed by cranial magnetic resonance imaging (MRI) scan. Scans were obtained at the time of admission except where patients required ventilatory support on admission.

\section{ANTICARDIOLIPIN ASSAY}

Anticardiolipin antibody was measured by an enzyme linked immunosorbent assay (ELISA) similar to that described by Loizou et al. ${ }^{33}$ Immulon I microtitre ELISA plates (Dynatech) were coated with $30 \mu \mathrm{l}(45 \mu \mathrm{g} / \mathrm{ml})$ of cardiolipin (Sigma, St Louis, Mo). The plates were blocked for non-selective binding with a $1 \%$ gelatin solution. Serum and cerebrospinal fluid samples were diluted 1:100 in 10\% fetal bovine serum; $200 \mu \mathrm{l}$ of each sample was placed in duplicate wells and incubated for two hours. The plates were then washed with a phosphate buffered saline solution with $0.05 \%$ Tween and $10 \%$ fetal bovine serum and developed with a 1:1000 dilution of goat antihuman IgG or IgM conjugated to horseradish peroxidase and 2,2'-azino-di-(3-ethylbenzthiazoline) sulphonate. The optical density at $405 \mathrm{~nm}$ was read on a Dynatech microELISA reader. Known negative and positive control sera were used as standards to correct for plate to plate variability. Control serum samples from 543 normal blood donors were used to standardise the assay. A value at or 
above the 98th centile was considered positive. In some cases serial titrations of sera were done and examined for the presence of aCL.

\section{Case reports}

CASE 1

A 36 year old woman with a long history of SLE, nephritis, renal failure and chronic haemodialysis, positive antinuclear antibody test, lymphopenia, and arthritis was admitted with grand mal seizures and respiratory arrest. Lumbar puncture showed $36 \times 10^{6}$ red blood cells/l and no white blood cells. A computed tomographic scan on admission showed mild ventricular enlargement and generalised atrophy. A clinical diagnosis of diffuse cerebritis was made and treatment with intravenous methylprednisolone was begun. Because of persistent need for continuing ventilatory support a cranial MRI scan was not obtained until eight days after admission. This showed punctate areas of abnormal increased intensity on intermediate and T2 weighted images in the subcortical and periventricular white matter, most marked in the left parietal region. There were patchy white matter changes in the subcortical white matter of the frontal and parietal lobes.

\section{CASE 2}

A 25 year old woman with a one month history of SLE characterised by arthritis, positive antinuclear antibody test, positive anti-DNA antibody, and glomerulonephritis had been treated as an outpatient with prednisone for nephritis, but then became psychotic, necessitating large doses of corticosteroids and suppression of her psychosis with haloperidol and chlorpromazine. On admission, an electroencephalogram disclosed bilateral temporal slowing. The cerebrospinal fluid showed $155 \times 10^{6}$ red blood cells $/ 1$, glucose $2.5 \mathrm{mmol} / 1$, and protein $520 \mathrm{mg} / \mathrm{l}$. C3 and C4 were normal.
Magnetic resonance imaging showed a recent right occipital infarct. The patient improved with tapering of corticosteroids and discontinuance of antipsychotic drugs.

CASE 3

A 61 year old woman with a 17 year history of SLE characterised by thrombocytopenia, cerebritis, glomerulonephritis, positive antinuclear antibody test, nasopharyngeal ulcers, and arthritis was admitted because of grand mal seizures and acute organic brain syndrome. On physical examination the patient was confused and disoriented. Neurological examination showed generalised hyperreflexia. The cerebrospinal fluid showed glucose $3 \mathrm{mmol} / \mathrm{l}$, protein $440 \mathrm{mg} / \mathrm{l}, 1 \times 10^{6}$ red blood cells $/ \mathrm{l}$, and $2 \times 10^{6}$ white blood cells/l. An electroencephalogram showed generalised slowing. Cranial MRI showed multiple gray and white matter lesions in both cerebral hemispheres and mild generalised atrophy. The patient was treated with intravenous methylprednisolone and rapidly improved. Follow up MRI one month later showed marked improvement in both gray and white matter lesions in the occipital lobes, mild improvement in the left parietal lobe, and a left pontine infarct.

\section{CASE 4}

A 17 year old woman with acute SLE characterised by malar rash, glomerulonephritis, Coombs' positive anaemia, thrombocytopenia lymphocytopenia, serositis, and a positive antinuclear antibody test was admitted with confusion and recurrent grand mal seizures. Physical examination showed disorientation, generalised hyperreflexia, bilateral extensor plantar responses, ataxia, and a tongue laceration. The cerebrospinal fluid showed no evidence of infection or haemorrhage. An electroencephalogram showed diffuse slow wave activity. A

Clinical and laboratory manifestations of patients with systemic lupus erythematosus and acute central neroous system lupus

\begin{tabular}{|c|c|c|c|c|c|c|c|c|c|c|c|}
\hline $\begin{array}{l}\text { Patient } \\
\text { No }\end{array}$ & Age & Sex & Diagnosis & $\begin{array}{l}\text { Clinical } \\
\text { manifestations }\end{array}$ & Admission $M R I^{*}$ & $\begin{array}{l}\text { Follow up } \\
\text { MRI }\end{array}$ & $\begin{array}{l}\text { Serum } \\
a C L^{*}\end{array}$ & $\begin{array}{l}C S F^{*} \\
a C L\end{array}$ & $R P R^{*}$ & $\begin{array}{l}P T^{*} \\
(s)\end{array}$ & $\begin{array}{l}P T T^{*} \\
(s)\end{array}$ \\
\hline 1 & 36 & $\mathbf{F}$ & Diffuse cerebritis & Seizures, coma & $\begin{array}{l}\text { Diffuse and patchy white } \\
\text { matter changes in left } \\
\text { parietal and bilateral } \\
\text { frontal and parietal lobes }\end{array}$ & None & $(-)$ & $(-)$ & $(-)$ & 12 & 32 \\
\hline 2 & 25 & $\mathbf{F}$ & $\begin{array}{l}\text { Diffuse cerebritis } \\
\text { (possible steroid } \\
\text { psychosis) and } \\
\text { cerebral infarction }\end{array}$ & Psychosis & Right occipital infarct & None & $(+)$ & $(-)$ & $(-)$ & $12 \cdot 1$ & 25 \\
\hline 3 & 61 & $\mathbf{F}$ & $\begin{array}{l}\text { Diffuse cerebritis } \\
\text { syndrome and } \\
\text { probable cerebellar } \\
\text { infarct }\end{array}$ & $\begin{array}{l}\text { Seizures, } \\
\text { organic brain } \\
\text { syndrome }\end{array}$ & $\begin{array}{l}\text { Multiple gray and white } \\
\text { matter changes in } \\
\text { cerebral hemispheres }\end{array}$ & $\begin{array}{l}\text { Left pontine } \\
\text { infarct, } \\
\text { improvement } \\
\text { in white } \\
\text { matter changes }\end{array}$ & $(+)$ & $(-)$ & $(-)$ & $12 \cdot 2$ & 24 \\
\hline 4 & 17 & $\mathbf{F}$ & $\begin{array}{l}\text { Diffuse cerebritis } \\
\text { syndrome }\end{array}$ & $\begin{array}{l}\text { Seizures, } \\
\text { organic brain } \\
\text { syndrome }\end{array}$ & $\begin{array}{l}\text { Occipital, frontal, and } \\
\text { left, parietal cortical } \\
\text { lesions; bilateral } \\
\text { cerebellar lesions }\end{array}$ & $\begin{array}{l}\text { Persistent left } \\
\text { cerebellar lesion }\end{array}$ & $(+)$ & $(-)$ & $(-)$ & $12 \cdot 3$ & 26 \\
\hline 5 & 21 & $\mathbf{F}$ & $\begin{array}{l}\text { Acute stroke } \\
\text { syndrome } \\
\text { (cerebral } \\
\text { infarct) }\end{array}$ & Left hemiparesis & $\begin{array}{l}\text { Right internal capsule } \\
\text { infarct, multiple } \\
\text { punctate white } \\
\text { matter changes in } \\
\text { left frontal and } \\
\text { parietal regions }\end{array}$ & $\begin{array}{l}\text { Residual right } \\
\text { internal capsule } \\
\text { infarct only }\end{array}$ & $(+)$ & $(-)$ & $(-)$ & $11 \cdot 4$ & 27 \\
\hline
\end{tabular}


Figure 1: Diffuse lupus encephalopathy. The T2 weighted spin echo magnetic resonance images

$(T R=2000 \mathrm{~ms} / T E=80 \mathrm{~ms})$ of patient 4 show extensive, reversible white matter lesions, which represent diffuse lupus

encephalopathy without

infarction. (a) This study shows extensive high

intensity lesions involving

the superficial and deep

white matter. (b) This image represents patient 4 after

eight days of corticosteroid treatment. Most high

intensity white matter lesions have resolved at this point. After one month, the magnetic resonance image was completely normal.
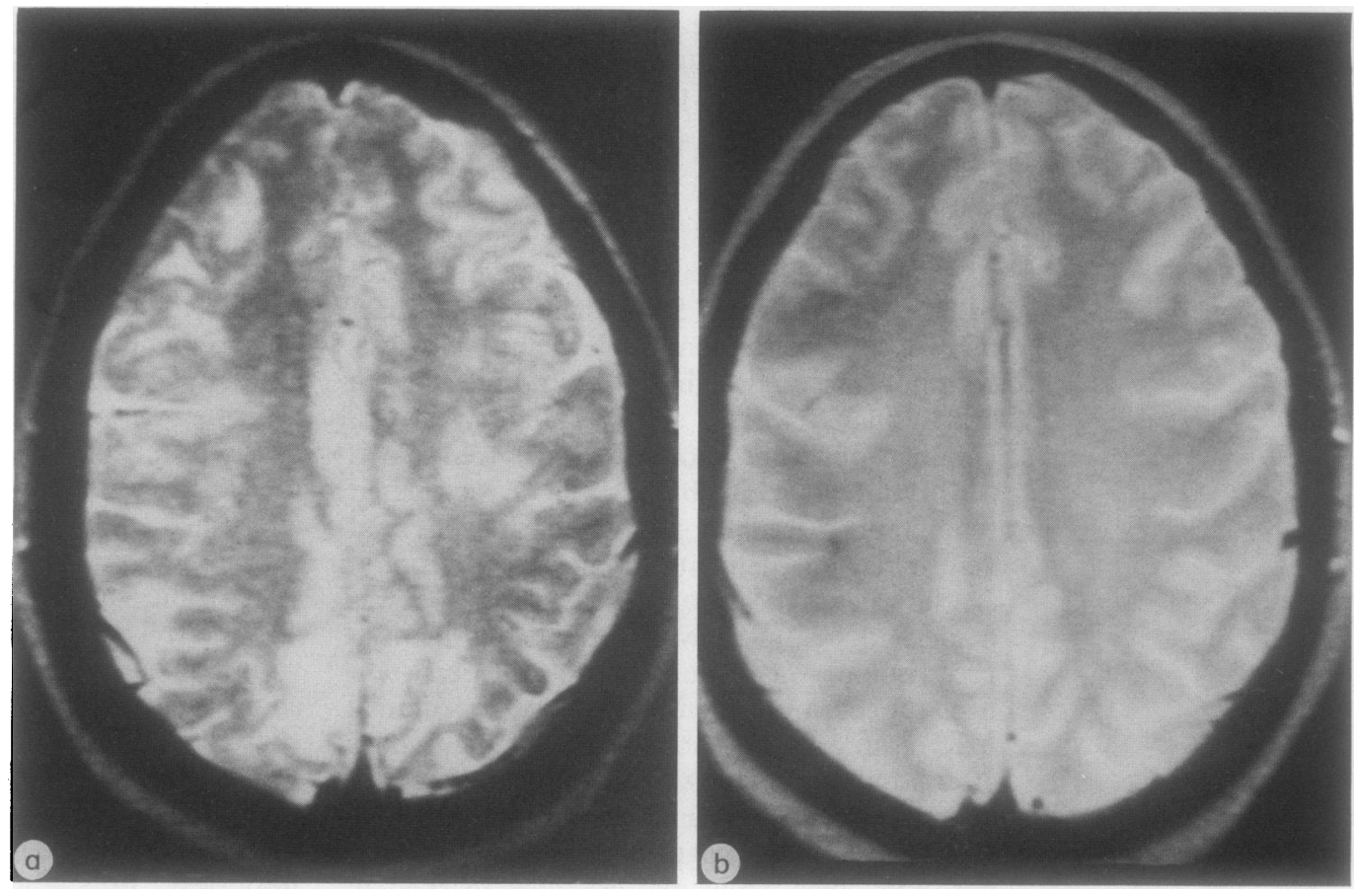

cranial computed tomogram was normal. Cranial MRI showed extensive high intensity areas in cortex extending to the edge of the white matter, including both occipital and frontal lobes, and the left parietal lobe. Large discrete lesions were present in both cerebellar hemispheres. The patient improved after treatment with intravenous methylprednisolone. An MRI scan taken eight days after admission showed complete resolution of all cerebral lesions, with one persistent cerebellar lesion consistent with infarct.

CASE 5

A 21 year old woman with SLE characterised by serositis, leucopenia, Coombs' positive anaemia,

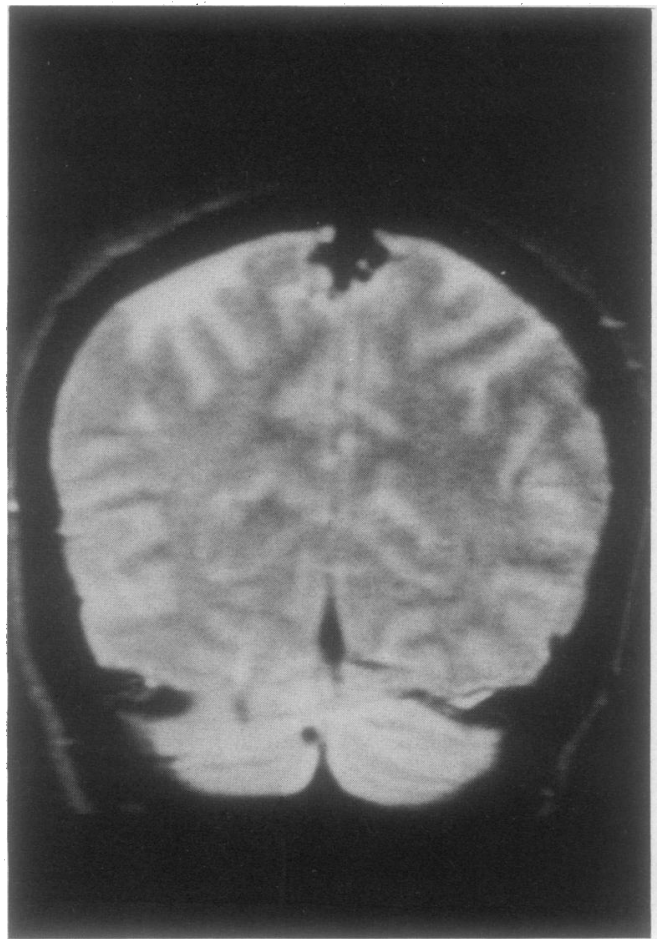

malar rash, and arthritis was admitted owing to acute onset of left upper arm weakness. Physical examination showed a left hemiplegia and malar rash. The cerebrospinal fluid showed no evidence of infection or haemorrhage. Cranial MRI showed acute infarction in the posterior limb of the right internal capsule with multiple punctate white matter changes in the left frontal and parietal regions. A subsequent follow up MRI scan after discharge showed only a persistent right internal capsule infarct.

\section{Results}

Four of the five patients with acute central nervous system lupus were positive for serum $\mathrm{aCL}$ (table). In none of the patients was $\mathrm{aCL}$ detected in the cerebrospinal fluid. Three of the patients with a diagnosis of diffuse cerebritis were positive for serum aCL, but again none of these had detectable cerebrospinal fluid levels. The isotypes and titres of the sera of the four patients were as follows: patient $2, \mathrm{IgG}=1 / 400$ $\operatorname{Ig} M=1 / 400$; patient $3, \operatorname{IgG}=1 / 100, \operatorname{Ig} M>1 /$ 1600 ; patient 4, IgG $>1 / 1600, \operatorname{IgM}>1 / 1600$; patient 5, IgG $>1 / 1600$, IgM $>1 / 1600$.

Figures 1 and 2 show representative lesions seen with MRI of diffuse lupus encephalopathy and cerebral infarction.

\section{Discussion}

In none of our five cases of acute central nervous system lupus were aCLs detectable in the cerebrospinal fluid. Four of the patients (Nos 1-4) had symptoms not readily explainable on the basis of infarct and therefore were felt to have diffuse cerebritis. A diagnosis of steroid psychosis in patient 2 was also a possibility. In patients 3 and 4 diffuse cerebritis was suggested by the transient nature or marked improvement of MRI lesions with corticosteroids. Both these patients (Nos 3 and 4 ) had serum aCL but 
neither had detectable cerebrospinal fluid levels. Of note, the serum and cerebrospinal fluid from patient 1 were negative for aCL. A possible association of serum aCL with cerebral thrombosis was confirmed in our patients. Four of our five patients (Nos 2-5) had persistent lesions on MRI, consistent with infarct. It should be emphasised that many of these 'infarct-like' lesions are not visible on conventional computed tomographic scans but such lesions are seen by MRI in lupus patients; thus infarct-like lesions may be a more accurate designation at this time. All four of these patients had serum aCL. In all patients both IgG and IgM were found and the titres were similar for both isotopes.

The absence of aCL in cerebrospinal fluid makes a role for aCL as a direct antineuronal antibody in acute cerebritis unlikely. Of note, even in the patients in whom disruption of the blood-brain barrier might have been expected (Nos 2-5) with MRI documented infarct there was no detectable aCL, even though those four patients had serum aCL. To show central nervous system production of an antibody rather than leakage based on a disrupted bloodbrain barrier it is necessary to show blood-brain barrier integrity by determining $Q$ albumin and IgG index. The complete absence of this antibody in cerebrospinal fluid in our cases of definite diffuse cerebritis (Nos 3 and 4) made this analysis unnecessary, however.

Anticardiolipin may be a marker antibody for patients at risk for acute central nervous system lupus Its absence in cerebrospinal fluid in our limited series seems to indicate that it does not play a part as a direct acting antineuronal antibody. Serum aCL was seen in all patients with infarcts, which suggests its presence may correlate strongly with lupus patients with cerebral infarcts. Cerebrospinal fluid determinations in a large number of patients would be useful to confirm our findings.

1 Harris E N, Loizou S, Englert H, et al. Anticardiolipin antibodies and lupus anticoagulant. Lancet 1984; ii: 1099.

2 Harris E N, Loizou S, Englert $\mathrm{H}$, et al. Cross reactivity of antiphospholipid antibodies. F Clin Lab Immunol 1985; 16: $1-6$.

3 Harris E N, Gharavi A E, Hughes G R V. Antiphospholipid antibodies. Clin Rheum Dis 1985; 11: 592-607.

4 Derksen R H W M, Bouma B N, Kater L. The prevalence and clinical associations of the lupus anticoagulant in systemic $185-92$.

5 Harris E N, Boey M L, Mackworth-Young C G, et al. Anticardiolipin antibodies: detection by radioimmunoassay and association with thrombosis in systemic lupus erythematosus. Lancet 1983; ii: $1211-4$.

6 Keane A, Woods R, Dowding V. Anticardiolipin antibodies in rheumatoid arthritis. $\mathrm{Br} \mathcal{F}$ Rheumatol 1987; 26: 346-50.

7 Fort J G, Cowchock F S, Abruzzo J L. Anticardiolipin antibodies in patients with rheumatic diseases. Arthritis Rheum 1987; 30: 752-60.
8 Hull R G, Harris E N, Gharavi A E, et al. Anticardiolipin antibodies occurrence in Behçet's syndrome. Ann Rheum Dis $1984 ; 43$ : 746-8.

9 Gastineau D A, Kazmier F J, Nichols W L, et al. Lupus anticoagulant: an analysis of the clinical laboratory features of 219 cases. Am $\mathcal{F}$ Hematol 1985; 19: 265-75.

10 Lechner K, Pabinger-Fasching F. Lupus anticoagulant and thrombosis. A study of 25 cases and review of the literature. Hemostasis 1985; 15: 254-62.

11 Triplett D A, Brandt J T, Musgrave $\mathrm{K} \mathrm{H}$, et al. The relationship between lupus anticoagulants and antibodies to phospholipid. FAMA 1988; 259: 550-4.

12 Elias M, Eldor A. Thromboembolism in patients with the "lupus"-type circulating anticoagulant. Arch Intern Med 1984; 144: $510-5$

13 Mueh J R, Herbst K D, Rapaport S I. Thrombosis in patients with the lupus anticoagulant. Ann Intern Med 1980; 92: $156-9$.

14 Feinstein D I. Lupus anticoagulant, thrombosis, and fetal loss. $N$ Engl f Med 1985; 313: 1348-50.

15 Carreras L O, Defreyn G, Machin S J, et al. Arteria thrombosis, intrauterine death and "lupus" anticoagulant: detection of immunoglobulin interfering with prostacyclin production. Lancet 1981 ; i: $244-6$.

16 Hart R G, Miller U T, Coull B U. Cerebral infarction associated with lupus anticoagulants-preliminary report. Stroke 1984; 15: 114-8.

17 Derksen R H W M, Bouma B U, Kater L. The association between the lupus anticoagulation and cerebral infarction in systemic lupus erythematosus. Scand $\mathcal{F}$ Rheumatol 1986; 15 ; $179-84$.

18 Asherson R A, Mercey D, Phillips G. Recurrent stroke and multi-infarct dementia in systemic lupus erythematosus: multi-infarct dementia in systemic lupus erythematosus: association with antipho

19 Estes D, Christian C L. The natural history of systemic lupus erythematosus by prospective analysis. Medicine (Baltimore) 1971; 50: 85-95.

20 Bluestein H G. Neuropsychiatric disorders in systemic lupus erythematosus. In: Lohita R G, ed. Systemic lupus erythematosus. New York: Wiley, 1987: 593-614.

21 Ellis S G, Verity M A. Central nervous system systemic involvement in systemic lupus erythematosus: a review of neuropatholorical findings in 57 cases. Semin Arthritis Rheum 1979; 8: 212-21.

22 Bennahum D A, Messner R P. Recent observations on central nervous system lupus erythematosus. Semin central nervous system lupus

23 Adelman DC, Saltiel E, Klinenberg J R. The neuropsychiatric manifestations of systemic lupus erythematosus: an overview. Semin Arthritis Rheum 1986; 15: 185-99.

24 Asherson R A, Derksen R H W M, Harris E N, et al. Chore in systemic lupus erythematosus and "lupus-like" disease: association with antiphospholipid antibodies. Semin Arthritis Rheum 1987; 16: 253-9.

25 Zvaifler N J, Bluestein H G. The pathogenesis of central nervous system manifestations of systemic lupus erythematosus. Arthritis Rheum 1982; 25: 862-6.

26 Colombek S J, Graus F, Eikon K. Autoantibodies in the cerebrospinal fluid of patients with systemic lupus erythematosus Arthritis Rheum 1986; 29: 1090-7.

27 Kelly M C, Benburg V A. Cerebrospinal fluid immunoglobulins and neuronal antibodies in neuropsychiatric systemic lupus erythematosus and related conditions. Systemic lupus erythematos 1987; 14: 740-4.

28 Wilson H A, Winfield J B, Lahita R G, et al. Association of IgG antibrain antibodies with central nervous systemic dysfunction in systemic lupus erythematosus. Arthritis Rheum 1979; 22: 313.

29 Bluestein H G, Williams G W, Steinberg A D. Cerebrospinal fluid antibodies to neuronal cells: association with neuropsychiatric manifestations of systemic lupus erythematosus. Am 7 Med 1981; 70: 240-6.

30 Bluestein H G. Neuropsychiatric manifestations of systemic lupus erythematosus. $N$ Engl f Med 1987; 317: 309-11.

31 Harris E N, Gharavi A, Boey M L, et al Anticardiolipin antibodies detected by a new solid phase radioimmunoassay: striking association with thrombosis [Abstract]. Ann Rheum Dis 1984; 43: 122

32 Tan E M, Cohen A S, Fries J F, et al. Revised criteria for the classification of systemic lupus erythematosus. Arthritis Rheum 1982; 25: 1271-7.

33 Loizou S, McCrea J D, Rudge A C, et al. Measurement of anticardiolipin antibodies by an enzyme-linked immunosorbent assay (ELISA): standardization and quantitation of results. Clin Exp Immunol 1985; 62: 738-45. 